\title{
8
}

\section{In Search of Virtual Learning Spaces for Sámi Languages}

\section{Hanna Outakoski}

The sense of self as a meaningful member of a community, and a sense of connection to ancestral lands, cultural traditions, family and relatives are often the core elements of Indigenous meaning-making and identity building processes (Smith 2008; Kuokkanen 2009; McCarty, Nicholas and Wyman 2012). Those with close connections to the culture, and who live in the proximity to Indigenous cultural and linguistic centres are more likely to be able to convey cultural heritage to the next generation. Jin Sook Lee and Eva Oxelson (2006: 455) summarise the importance of knowing and being proficient in a heritage language by saying that for the speakers and learners,

Losing proficiency in their heritage language is more than just a loss of a linguistic system; it is a separation from their roots, a denial of their ethnic identity, and a dismissal of their potential as a bilingual and bicultural member of society.

Although Lee and Oxelson refer to children and young learners, I believe this to be true of adult heritage language learners as well. 
In Sápmi, ${ }^{1}$ the land of the Sámi, physical distances between the speakers of a certain Sámi language or a dialect can be so huge that daily face-toface meetings are often impossible to arrange. The Sámi who live in the periphery of Sápmi, that is, some distance away from the cultural centres, may also have a hard time finding adequate linguistic and cultural arenas that can support and strengthen their Indigenous identity and linguistic connection to the heritage language. The same is even more evident in the case of those Sámi who have, for different reasons, moved out of the traditional settlement areas of their families and kin. For such individuals, the personal connections and occasional visits to the home community may be the only tie to the place of origin. Creation of new local (and often urban) language arenas and the possibility of meeting and interacting with other speakers of Sámi (preferably with the right language or dialect) becomes very important, and sometimes the only way of nurturing Sámi identity. Sámi identity in the real world is thus closely tied to the links that individuals have to certain spaces, locations, skills, language and people.

For language maintenance and development to take place, proximity to other speakers is as important as the closeness to cultural arenas and the connection to the past. For the Sámi, a part of the present language maintenance struggle is related to the fact that fluent speakers of the language often live in 'language pockets' far from learners, in communities where the language is still used in many areas of private and official communication with others. It is among such speakers that I find the most prominent teachers of both language and traditional knowledge. So, not only is the Sámi population getting more scattered and influenced by increased mobility, but the concentration of the language speakers does not (necessarily) follow the trajectories of the learners. Many people must choose between staying in the language community and leaving in search of a living.

High speaker density in a community is positive for language maintenance (e.g. see Grenoble and Whaley 1998: 49 on the case of Māori), while low speaker density, especially in urban areas, tends to be an impeding factor for language maintenance and development. However, among

1 Sápmi reaches from the Kola Peninsula in Russia sweeping over the northern municipalities of Finland to the mountain lands of mid-Sweden and mid-Norway. Many Sámi live outside Sápmi, for example, in the Nordic capitals of Helsinki, Stockholm and Oslo. There are several linguistically distinguished Sámi languages of which nine still remain at the time of writing. Some of the smallest varieties are under a serious threat of disappearing and even the largest Sámi language, North Sámi, is estimated as having a maximum of 15,000 speakers left. 
others, Claire Bernard et al. (2008) have in their mathematical models shown that the negative impact of low speaker density numbers on the maintenance of viability and resilience of endangered languages can be fought when focused educational and political efforts are directed to strengthening the endangered language. One such effort, as suggested by the author, is the development and advancement of distance education in Sámi languages that utilises all the different aspects, applications and teaching tools of present day online education.

Umeå University, as with many other institutions for higher education worldwide has, since the beginning of the twenty-first century, seen an increase in demand for online courses. As a consequence of the recognition of such a demand, the university has amended and adjusted a great amount of the course offerings to meet students' wishes to study online or at a distance. A mix of different flexible learning solutions is used by various departments to accommodate these new online courses. Sámi courses at Umeå University are no exception. However, while many other subjects can be studied online without great adjustments to the course setup, teaching languages (and especially beginner courses) comes with extra challenges. Simply sharing information and documents via a common learning platform and having a discussion or chat forum on the internet will not be enough when the students are expected to train their communicative skills and to engage in extensive meaning-making processes.

In search of a teaching model that can do all of the above, I have focused on virtual learning environments in which real-time interaction (voice, chat, movements, visual cues) between students and/or with the teacher are made possible. Online courses should, not simply be storage places of information, which students are expected to internalise. A good online language course should give students possibilities for communicative training, as do campus courses. This, in turn, means that one may have to compromise on the flexibility of the course when it comes to synchronicity (virtual meetings and co-working in a virtual environment require planning and predefined schedules) and the number of participants must be manageable. The two main arguments (flexibility and capacity) used for promoting online education in general are thus, in the view of the author, not going to be the strongest arguments for online language teaching in particular. In the case of Sámi online education, the main arguments in favour of online teaching models have to do with accessibility, that is, the fact that they make the education available for a group of learners that are 
geographically scattered and not in proximity to other heritage language learners. The second argument has to do with the benefits of the relative anonymity of online courses; learners of Sámi often carry with them an emotional load that has discouraged them from speaking and using the language in their private lives.

With the nature of the heterogeneous Sámi language community in mind, virtual learning environments ${ }^{2}$ offer the possibility of bringing together learners and speakers of endangered languages that would not be likely to form learner groups otherwise. Further, virtual 3D environments (such as SecondLife or OpenSim) offer the possibility of adjusting and altering the teaching environment to resemble, in as much detail as possible, the settings for natural learning situations. This, in turn, gives the online Sámi language teacher the opportunity to teach speakers and learners of Sámi in a setting that can, in the best case, strengthen the ties to the ancestral place of origin and, at the same time, offer the learner a language learning experience that frees them from potential internal stigmas. Diving into the complexity of language, its syntax, semantics and pragmatic levels in a nontraditional learning environment (as opposed to a traditional class room environment) can also accommodate the needs of learners with different learning styles (for more on learning styles, see Kolb 1984; Dunn 2000).

Hanna Outakoski (2014) offers a detailed description of a pedagogical project that has had as its goal to create a teaching model or solution for online courses in Sámi languages. The challenge has been to find a way to replace, or at least to complement, physical face-to-face meetings by online teaching situations where the same communicative, linguistic and pragmatic learning goals can be met as in the traditional campus courses. The approach presented in Outakoski (2014) is flexible enough to accommodate different takes on online teaching, varying from fully fledged online scenarios to the use of online tools as complementary features to traditional campus courses. The project described in Outakoski (2014) is one of the core approaches to online language education behind the Euroversity Good Practice Framework. This framework was designed by Euroversity, a European Union networking project that aimed at supporting teachers from different disciplines who teach, or were planning to teach in, or with the help of, virtual worlds. Outakoski's approach recognises the

2 By virtual learning environments I mean the mix of different online applications, programs, learning platforms, social forums and other learning environments designed for education that for the most part happen online. 
potential of 3D virtual environments as new Indigenous learning places, but also identifies challenges having to do with technical, financial and epistemological issues (discussed briefly in Motteram et al. 2014).

3D learning environments can thus aid the teaching of an Indigenous language in many different ways. A concrete example of such a bridging between the language and its learning environment is how we can aid understanding of space and location in a language that morphologically marks direction and spatiality in the language. In the virtual environment, the teacher and the student can interact and engage in meaning-making processes in a way that resembles the same processes in the real world. The spatiality expressed in the language (e.g. by different cases or adpositions) can be trained both in a traditional way working on paradigms and grammar exercises, and through interactive $3 \mathrm{D}$ world training where the word forms can be tied to actions, locations and movement. Therefore I argue that virtual environments have a tremendous potential to create a versatile tool kit for teaching an endangered language at a distance to students that otherwise lack access to important language domains and arenas.

\section{References}

Bernard, Claire, Laetitia Chapel, Guillaume Deffuant, Sophie Martin and Maxi San Miguel. 2008. 'Maintaining viability and resilience of endangered languages'. Working paper. European project PATRES. Online: www.patresproject.eu/images/f/ff/viability_languages_v3.pdf (accessed 16 June 2018).

Denzin, Norman K. and Y.S. Lincoln (eds). 2008. The Landscape of Qualitative Research. Thousand Oaks, CA: Sage Publications Inc.

Dunn, Rita. 2000. 'Learning styles: Theory, research, and practice'. Applied Educational Research Journal 13(1): 3-22.

Euroversity Network. Online: www.euroversity.eu (accessed 19 June 2018).

Grenoble, Lenore A. and Lindsay J. Whaley (eds). 1998. Endangered Languages: Language Loss and Community Response. Cambridge: Cambridge University Press. doi.org/10.1017/CBO9781139166959

Grenoble, Lenore A. and Lindsay J. Whaley. 1998. 'Toward a typology of language endangerment'. In Endangered Languages: Language Loss and Community Response, edited by Lenore A. Grenoble and Lindsay J. Whaley, 22-54. Cambridge: Cambridge University Press. doi.org/10.1017/CBO978113 9166959.003 
Jager, Sake, Linda Bradley, Estelle J Meima and Sylvie Thouësny (eds). 2014. CALL Design: Principles and Practice. Dublin: Research-publishing.net.

Jones, Mari C. and Sarah Ogilvie (eds). 2014. Keeping Languages Alive: Documentation, Pedagogy and Revitalization. Cambridge: Cambridge University Press.

Kolb, David A. 1984. Experiential Learning: Experience as the Source of Learning and Development. Englewood Cliffs, NJ: Prentice-Hall.

Kuokkanen, Rauna. 2009. Boaris Dego Eana: Eamiálbmogiid Diehtu, Filosofijat Ja Dutkan [Old as the Earth: Indigenous Knowledge, Philosophies and Research]. Kárášjohka: ČálliidLágádus.

Lee, Jin Sook and Eva Oxelson. 2006. "'It's not my job”: K-12 teacher attitudes toward students' heritage language maintenance'. Bilingual Research Journal 30(2) 453-77, doi.org/10.1080/15235882.2006.10162885

McCarty, Teresa L., Sheilah E. Nicholas and Leisy T. Wyman. 2012. 'Reemplacing place in the "global here and now" - critical ethnographic case studies of Native American language planning and policy'. International Multilingual Research Journal 6(1): 50-63, doi.org/10.1080/19313152.201 2.639244

Motteram, Gary, Ton Koenraad, Hanna Outakoski, Kristi Jauregi, Judith MolkaDanielsen and Christel Schneider. 2014. 'The Euroversity Good Practice Framework (EGPF) and its application to minority languages and elder learners'. In CALL Design: Principles and Practice, edited by Sake Jager, Linda Bradley, Estelle J Meima and Sylvie Thouësny, 241-47. Dublin: Researchpublishing.net, doi.org/10.14705/rpnet.2014.000225.

OpenSimulator. Online: opensimulator.org/wiki/Main_Page (accessed 19 June 2018).

Outakoski, Hanna. 2014. 'Teaching an endangered language in virtual reality'. In Keeping Languages Alive: Documentation, Pedagogy and Revitalization, edited by Mari C. Jones and Sarah Ogilvie, 128-39. Cambridge: Cambridge University Press.

Second Life: Your World, Your Imagination. Online: secondlife.com/ (accessed 28 June 2018).

Smith, Linda Tuhiwai. 2008. 'On tricky ground: researching the native in the age of uncertainty'. In The Landscape of Qualitative Research, edited by Norman K. Denzin and Y.S. Lincoln, 113-44. Thousand Oaks, CA: Sage Publications Inc. 
This text is taken from Indigenous Efflorescence: Beyond Revitalisation in Sapmi and Ainu Mosir, edited by Gerald Roche, Hiroshi Maruyama and Åsa Virdi Kroik, published 2018 by ANU Press, The Australian National University, Canberra, Australia.

doi.org/10.22459/IE.2018.08 